\title{
El VIAJE DEL PINTOR JUAN DE UCEDA A LIMA
}

En la bibliografía del pintor sevillano Juan de Uceda Castroverde (hacia 1570-1631) se advertía una laguna correspondiente a los años 1608-1609, toda vez que su cronología se había establecido casi año por año desde 1593 a $1631^{1}$, sin que hasta ahora se hubiese podido encontrar explicación a este vacío documental.

Por documento inédito que ahora damos a conocer ${ }^{2}$ sabemos que el 12 de diciembre de 1608 Juan de Uceda pide en la Casa de Contratación licencia para embarcarse a Indias y trasladarse por necesidad forzosa a la ciudad de Lima «a dehar asentado çiertos negosios que tengo tratado y comunicado (sic) por cartas que enviado y me an respondido çiertas personas vecinas de la dicha ciudad, sobre la fábrica de retablos de pinturas, que es mi arte, para el seruicio de ygleçias perroquiales y monasterios y conventos de frayles y monjas de la dicha çiudad...." ${ }^{3}$.

En dicha petición advierte que le acompañarán un oficial y un criado y señala expresamente que se traslada por plazo no superior a tres años contando con el consentimiento de su esposa doña María de Berastegui ${ }^{4}$.

En el documento de petición de licencia Uceda presenta a tres testigos que son el conocido pintor Juan de Salcedo ${ }^{5}$, el ensamblador Cristóbal Arcos y el vecino de Sevilla Juan de Aldana. El primero señala en su testimonio tener setenta años y conocer a Uceda desde hace seis y destaca la categoría del pintor en su oficio, indicando que marcha a las Indias para trabajar en retablos de iglesia no por deudas ni delitos.

La vuelta de Uceda a Sevilla debió producirse dentro de los términos establecidos, pues sabemos que en 1610 concierta las pinturas del retablo de San Juan Bautista del convento sevillano de Santa María del Socorro. Independientemente de las obras concertadas y realizadas durante su estancia en Lima, debió también contactar con posibles comitentes para futuros trabajos, pues ya desde Sevilla el pintor envía en 1613 diecisiete cuadros a través del escultor Gaspar de la Cueva ${ }^{6}$.

También es interesante para subrayar la posible trascendencia de la estancia de Uceda en Lima, la noticia de que su único hijo conocido, Gaspar, muere en la citada ciudad americana en 1621, ya que en 1622 nuestro pintor da poder al escultor Gaspar de la Cueva y al pintor Fabián Gerónimo, vecinos de Lima, para que le cobrasen la herencia de su hijo Gaspar, muerto precisamente en Lima, lo que parece asegurar una vinculación profunda 7 .

No se ha señalado hasta ahora ninguna obra que pueda ser atribuida a nuestro artista en el

\footnotetext{
1 Valdivieso, E., y Serrera, J. M., Pintura sevillana del primer tercio del siglo XVII, CSIC, Madrid, 1985, pp. 196-203.

2 Agradezco desde estas páginas la gentileza de la investigadora Conchita Romero al facilitarme la presente documentación y a Mercedes Agulló su ayuda en la transcripción del mismo.

3 Archivo General de Indias, Contratación, 5313, n. 72, folio 1-5 (Juan de Useda. Sobre pasar a Indias El año de 608). Justo el año anterior de la partida de Uceda a Lima el 30-XII-1607 el pintor tasa las esculturas que había ejecutado Juan Martínez Montañés para el retablo de las Concepcionistas de Lima. Cfr. Sancho Corbacho, H., «Documentos para la Historia del Arte en Andalucía", vol. II, Sevilla, 1930, pp. 231-232.

${ }^{4}$ Uceda había contraído matrimonio con doña María de Verastegui o Berastegui el 28-VII-1593 en la parroquia sevillana de la Magdalena. Cfr. Valdivieso-Serrera, 1985, p. 196.

${ }_{5}$ Este artista está documentado en Sevilla desde 1570 a 1616 y en 1604 trabaja conjuntamente con Uceda y un tal Francisco Juanete en los estandartes y gallardetes y otras cosas para la galera real capitana de España por mandato del Conde de Niebla. Cfr. López Martínez, C., Arquitectos, Escultores y Pintores vecinos de Sevilla, Sevilla, 1928, p. 143. En el documento dice tener setenta años de edad.

6 Marco Dorta, E., Fuentes para la Historia del Arte Hispanoamericano, vol. II, Sevilla, 1960, pp. 301-304.

7 Muro Orejón, S., Documentos..., vol. VIII, Sevilla, 1935, p. 75.
} 
Perú. Quizás la publicación de esta noticia pueda orientar a los investigadores peruanos o a americanistas familiarizados con los fondos conservados en Museos o iglesias limeñas para localizar las obras que hayan podido conservarse hasta hoy.

Benito Navarrete Prieto Universidad de Alcalá de Henares 